\title{
1916: UM ANO DE REVISTAS LITERÁRIAS
}

\author{
1916: A YEAR IN PORTUGUESE LITERARY MAGAZINES \\ Ricardo Marques"
}

Resumo: Como se sabe, o tempo da Primeira República (1910-1926) foi um tempo instável. Cerca de 40 governos em 16 anos perfizeram uma média de 3 governos por ano, mediado por grande descalabro financeiro e assassínios e golpes de estado sangrentos.Partindo dessas duas revistas fundamentais do Modernismo Português (Exílio e Centauro), o propósito da nossa comunicação será o de preencher o espaço por vezes nebuloso que existe à sua volta, mostrando um panorama rico de publicações periódicas, de norte a sul do país, com os mais diversos protagonistas e intuitos, mas apresentando igualmente continuidades e pontes.

Palavras-chave: Primeira República; Modernismo Português; Revistas Literárias

ABSTRACT: As is known, the time of the First Republic (1910-1926) was an unstable time. About 40 governments in 16 years mean an average of 3 governments per year, mediated by large financial catástrofe, assassinations and bloody coups.Departing from these two fundamental magazines of Portuguese Modernism (Exílio and Centauro), the purpose of our paper is to fill the space at times nebulous nebulous that there is around, showing a rich panorama of periodicals, from north to south, with the most diverse protagonists and motives, but also presenting continuities and bridges.

KEYwords: First Republic; Portuguese Modernism; Literary magazines

\footnotetext{
"IELT/FCSH-Universidade Nova de Lisboa - Bolseiro de Pós-Doutoramento FCT SFRH/BPD/101758/2014. Email: ricardomfm@gmail.com
} 
De um modo geral, existem cerca de 40 publicações periódicas de interesse literário surgidas no ano de $1916^{1}$, um pouco por todo o país. Para este conceito de 'publicação periódica' convergem sobretudo dois tipos de publicação: em primeiro lugar, revistas de carácter e linha estética muito particulares, como é o caso de Exílio e Centauro, as revistas que hoje celebramos, e jornais de interesse literário, na maior parte dos casos menos interessantes desse ponto de vista.

As publicações periódicas, normalmente vistas como de somenos importância, dada a sua efemeridade, dão-nos informações muito importantes sobre: autores e editores, época social-cultural-política em que estes escreveram, as efemérides e canonizações de autores falecidos, publicidades, bem como permitem traçar os locais em que se encontra alguma actividade cultural. A sua característica principal acaba por ser, precisamente, um testemunho válido e fidedigno do contexto em que foram publicadas.

Penso estarmos todos cientes que estes dois números de Exílio e Centauro representam uma invectiva de arrière-garde no que toca ao modernismo experienciado em Orpheu no ano anterior. Esta linha simbolista e decadentista das duas revistas, que atinge picos de qualidade, por exemplo, nos poemas inéditos de Pessanha em Centauro, que mais tarde surgirão em Clepsidra (1920),

\footnotetext{
${ }^{1}$ Baseio os meus cálculos não só nas minhas próprias pesquisas na Biblioteca Nacional de Lisboa, mas igualmente nas resenhas descritivas presentes nos livros de Fernando Guimarães, Simbolismo, Modernismo, Vanguardas, Porto, Lello \& Irmãos, 1992 [1982], Clara Rocha, Revistas Literárias do século XX em Portugal, Lisboa, INCM, 1985 e Daniel Pires, Dicionário da Imprensa Periódica Literária, 1900-1940, primeiro tomo, Lisboa, Grifo, 1996.
}

esta linha simbolista não causa o impacto da revista do ano transacto. Para ser exacto, estas revistas talvez estivessem nesse 'ponto de confluência' entre uma réstia de simbolismo do fim do século anterior e um ousado e recente futurismo, de que nos fala Nuno Júdice na abertura da sua edição de Centauro. O Modernismo destas duas revistas que hoje celebramos aproxima-se talvez de um conceito de 'Modernismo' presente nas letras hispano-americanas da altura, de onde temos tantos e valorosos exemplos - Delmira Agustini (1886-1914), Leopoldo Lugones (18741938) ou Herrera y Reissig (1875-1910).

Por motivos óbvios de tempo e de estruturação de ideias trago apenas alguns exemplos paralelos a Exílio e Centauro, mas que as acompanham na viagem de 1916.

Uma rápida análise deste período permite-nos perceber que, do ponto de vista do conteúdo, não é só a poesia e o folhetim narrativo que aparece nas revistas literárias - o teatro tem uma grande importância. 1916 foi um ano em que surgiram 3 revistas focadas no mundo do teatro e dos espectáculos em geral. Daniel Pires, no seu Dicionário da Imprensa Periódica Literária (1900-1940), dá-nos conta de mais de 30 revistas com este enfoque para todo o período da primeira república.

As revistas que surgem neste ano são todas sediadas em Lisboa: A Comédia de Lisboa, A Ribalta, A Pateada, nomes alusivos a esta área artística. Nelas escrevem mais ou menos os mesmos críticos, por vezes também eles dramaturgos e poetas, que vêm de outras publicações sobre teatro em todo o período: 
Alfredo Pinto (Sacavém), André Brun, Félix Bermudes, Afonso Lopes Vieira, Gustavo Sequeira, entre outros. ${ }^{2}$

Muito interessante, ainda que não seja puramente uma publicação literária, é o Almanach de Palcos e Salas, uma colecção vinda já do século XIX (1888), organizado por um destes críticos, Gustavo Sequeira, que apresentava uma miscelânea de artigos, música e trechos de peças conhecidas para cada ano. São volumes muito importantes e válidos como documento sócio-cultural de uma época em que vários teatros funcionavam na cidade de Lisboa. Através da análise cruzada de figuras, espaços e textos, podemos ler quem eram os protagonistas, e o gosto coevo, as ideias de teatro. "Modernismo", por exemplo, é palavra que aparece uma vez, ao falar de uma actriz do período-Albertina de Oliveira.

Analisado o almanaque do ano de 1917, uma vez que os textos eram escritos maioritamente no ano anterior [1916], pode-se perceber um maior afluxo de Nacionalismo. É caso paradigmático o poema 'Pátria' de Joaquim dos Anjos, morto dois anos depois, em 1918, tipógrafo e poeta e figura finissecular de relevo, tradutor de Victor Hugo, etc.

Lemos igualmente neste almanaque a continuação de um certo parnasianismo finissecular, como em António Feijó, poeta e diplomata de Ponte de Lima, que veio a falecer em Estocolmo, onde estava em serviço, e que dedica um poema de tom fúnebre à sua mulher sueca, recentemente morta.

Como nos lembramos, Guerra Junqueiro tem um retrato inédito publicado em Exílio. A enaltação de figuras patriarcais da literatura do passado é uma constante nas revistas literárias do primeiro modernismo, e 1916 não foi excepção. Na verdade, o ano começa logo com uma publicação literária em volume único, que pretende ser, de acordo com o subtítulo, um "arquivo de matérias para um monumento litterario ao Grande Escritor Camillo Castello Branco" e dá pelo nome de Camilliana. Saído no Porto no dia I de Janeiro, é um belo exemplar, o que está na Biblioteca Nacional, com uma foto inédita até então do escritor, e com pormenores estéticos bem ao gosto da época (como os motivos art nouveau dos bordos ou dos incipit).

Camilliana, 'ponto de concentração e convívio de todos os que professam o culto camiliano', como nos diz Alfredo de Faria no editorial, não pretendia ser um acto isolado, estando 'no seu programa a reedição de interessantissimos folhetins [...] do Mestre'. Não foi, porém, o que aconteceu. A revista apenas teria este número único, mas inclui logo colaboradores de peso: Eduardo Sequeira, Pinheiro Chagas, Sebastião Lima.

\footnotetext{
2 Para quem se interesse por estes aspectos da vida teatral, ainda que não lida pelas publicações periódicas literárias, recomenda-se $O$ Teatro de Lisboa no Tempo da Primeira República, de 2004 (INCM), da autoria de Glória Bastos e Ana Isabel Vasconcelos.
} 
Legenda: Capa do número único da publicação "Camilliana”

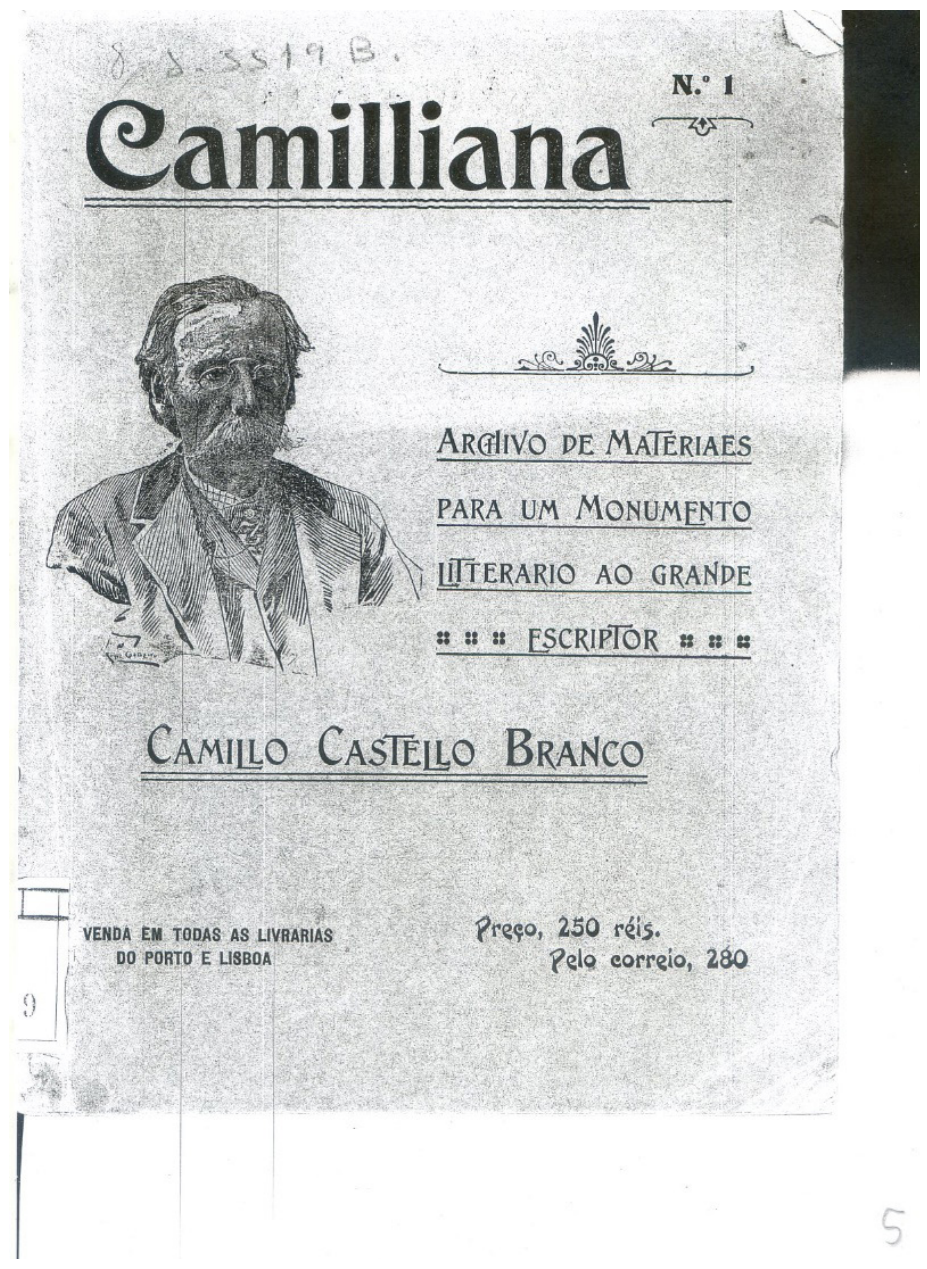

Já Gente Lusa (1916-17) foi uma revista igualmente surgida em Janeiro e que percorre em 10 números e 2 séries todo o ano de 1916 e 1917. A sua índole, como o nome indica, é eminentemente nacionalista, paralela à de Exílio e Centauro. "In Hoc Signo Vinces", máxima cristã do imperador Constantino I aparece associado ao título logo na capa - Gente Lusa. Veja-se agora o seu subtítulo - Arquivo - a revista está sempre com um pé no presente e outro no passado, publicando inéditos do início do século e do fim do século anterior.
Camilo e Manuel Laranjeira são autores homenageados no afã de compilar informação de referência sobre o que designam como 'Letras e Artes portuguesas'. Nele colaboram variadíssimos autores, alguns ainda hoje lidos e estudados, como é o caso de Leonardo Coimbra ("Aspectos da Vida Religiosa (notas)", datado de Dezembro de 1915), e inclui um inédito de Júlio Brandão.

O seu propósito, logo denotado no primeiro número é inequívoco: 
'Não temos programa; não fazemos promessas.

Gente Lusa não ousa disputar primazias às suas irmãs ilustres, tão pouco pretende marcar nas letras e nas artes pátrias o lugar que caberia a um esforço pioneiro.

A sua aparição traduz - quando muito - a aspiração de gente moça para quem a vida é uma primavera constante, um campo de luta onde apraz entrar quichotescamente, com o coração cheio de fé e de vizeira erguida.

A sua obra não será fecunda, mas o seu esforço é generoso e são; as suas páginas não conduzirão à imortalidade através dos domínios da erudição, da arte e da filosofia, mas hão-de com certeza encerrar aquela parcela mínima de Beleza sem a qual a Vida seria uma eterna via dolorosa.

Nascida numa terra de glorioso passado Gente Lusa processará o culto nobilíssimo da Tradição, não para diante dela se quedar em contemplação doentia, antes muito singelamente para na sua força salutar beber alentos para a realização de uma tarefa bem digna da terra portuguesa.

Aos novos, àqueles que, como nós, crêem e sonham, iremos pedir um pouco da sua Fantasia - dessa Fantasia que vôa tão alto no céu azul como o bando de gaivotas que, ruflando as asas, neste momento passa sobre as nossas cabeças e, em lentos e caprichosos volteios, vai, lá longe, em pleno mar, beijar a crista rendilhada das ondas...'

Retomarei este programa mais à frente. Para já, é de notar que esta relevância da 'terra portuguesa' é algo que se traduz igualmente nas opções estéticas dos directores da revista. António Carneiro, o pintor portuense, é um grande colaborador na sua parte estética. Em todos os números aparece um desenho seu, normalmente submetido ao tema do número. No caso do primeiro e do segundo, serão respectivamente Camilo e Manuel Laranjeira que aparecerão. No terceiro número aparece o desenho de uma Ronda, uma roda de mulheres dançando, aspecto bem tradicional da cultura portuguesa. Já o número quatro e o número cinco revelam duas fotografias, uma do claustro do Pilar, e outra de uma escultura da figura mitológica de Baco, da autoria de Teixeira Lopes (foto sem indicação de autoria). Nos 5 números da II série, já de 1917, aparecerá uma miscelânea de suportes e auto: no número 1 é a fotografia de uma jarra ("Manoel Bernardes") vista numa exposição em Lisboa, alusão às conquistas dos descobrimentos, fabricada na Fábrica da Torrinha, em Gaia. Número 2 é um desenho de Eça por António Carneiro, o número 3 volta a ser uma fotografia, desta feita do Mosteiro do Grijó, no número 4 um desenho de Carneiro - La Bilbaínita, uma alusão a um artigo, algumas páginas antes sobre “Sete Danças de 'La Bilbaínita', de Manuel de Sousa Pinto. O último número tem a mais-valia de um desenho de Domingos Sequeira, de índole mitológica.

Esteticamente, há uma evolução na gramática estética, no sentido de ainda mais denotar este nacionalismo e de uma maior complexificação do desenho. Adicionalmente, e contrariamente a muitas revistas do período, esta não apresenta qualquer publicidade. 
Legenda: Capa interior do ${ }^{\circ} 5$ da revista "Gente Lusa"

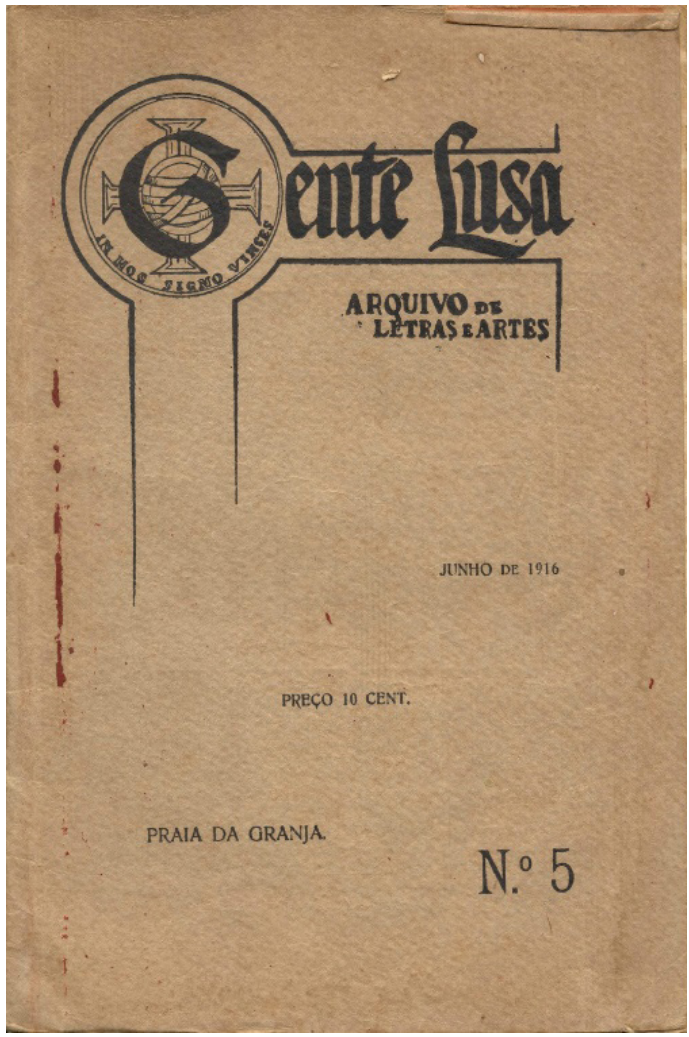

Curiosamente, no primeiro número, dedicado a Camilo, aparece uma crítica muito favorável à Camilliana (coluna intitulada de "Livros", a última página de Gente Lusa, escrita por Ruy Vaz, o mesmo crítico de arte que colabora daí a dez anos em Athena, com Pessoa). Aliás, toda a secção é dedicada a Camilo visto o outro livro recenseado ser uma nova edição de A Brasileira de Prazins, na colecção 'Lusitania', seu décimo quarto volume, editada nada mais nada menos do que pelos importantes livreiros senhores Lello \& Irmãos", a livraria que todos conhecemos ainda no Porto. Uma colecção que já teria então o Menina e Moça de Bernardim
Legenda: Capa do $1^{\circ}$ número da Série II da revista "Gente Lusa"

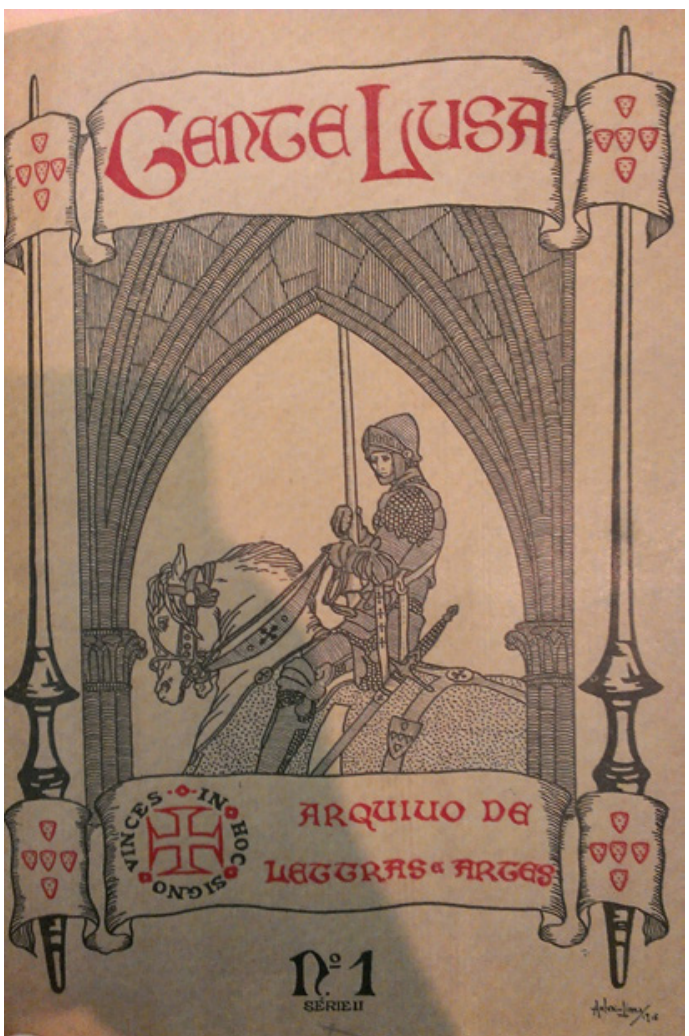

Ribeiro, por exemplo, e que é recomendada encomiasticamente por Ruy Vaz quer pela "modicidade do seu preço, quer pela sua original e primorosa apresentação".

Por último, "Ramalho e Bruno" é o nome de um artigo de Pinto de Ribalda (talvez pseudónimo), onde se fala das mortes recentes (em Setembro e Novembro de 1915, respectivamente) dos dois grandes vultos das letras de então e de sempre.

O segundo número é dedicado a Manuel Laranjeira (1877-1912), escritor e pensador de Santa Maria da Feira. Suicidado aos 35 anos depois de uma batalha difícil e constante com a sífilis, que contrai criança, era um culto e 
letrado médico, exemplo de um certo pessimismo finissecular.

Nos números seguintes $(3,4$ e 5$)$ não parece haver uma consagração temática a uma personalidade. Laranjeira e Camilo aparecem dispersamente, sejam como autores em nome próprio (cartas inéditas, sobretudo) sejam como autores estudados. António Augusto Soares de Passos (1826-60), figura portuense conotada com o Ultra-Romantismo, aparece brevemente no número 3, porém, com cartas escritas durante a Revolução de 1851.

Na recensão literária, a partir do terceiro número há igualmente uma mudança de crítico. Ruy Vaz é substituído pelos pseudónimos - Aquiles e Pátroclo. Dada a alusão grega, é muito possível que este seja pseudónimo de Narciso de Azevedo (1888-1969), tendo em conta igualmente as suas poesias dispersas na segunda série, sempre com citações clássicas e de um pendor sexualizante muito indirecto. Esta pista é-nos dada por uma nota dos próprios Aquiles e Pátroclo, numa recensão a um livro de odes à maneira de Horácio da autoria do jovem poeta António Ferreira. É-nos assim dito na recensão: "No próximo número publicaremos sobre as Horacianas uma apreciação de Narciso de Azevedo." O que acabou por não suceder, diga-se.

Um pormenor curioso das recensões e nótulas, o que não abona a favor da idoneidade e da imparcialidade que deviam ser características deste tipo de labor, é que alguns dos autores recenseados são ou foram colaboradores de Gente Lusa, como é o caso de António Carneiro (recenseado nas nótulas finais com uma alusão a uma exposição a decorrer nessa altura), de Júlio Brandão, ou de Eduardo Pimenta, de António de Lima. Esta estratégia funciona duplamente como um auto-elogio da própria revista, bem como de um proteccionismo do talento 'da Terra de glorioso passado' que é o Porto, como nos é dito no editorial.

Terra Nossa é o meu exemplo final. A sua importância centra-se fundamentalmente no facto de uma versão inicial de "A Ceifeira" aparecer no terceiro número, de Setembro de 1916 (Mensal, $1^{\circ}$ é em Maio), versão que é depois revista quando aparece em Athena, $\mathrm{n}^{0} 3$, 1924, e que é próxima daquela que conhecemos (retira uma estrofe e reescreve dois versos). Curiosamente, é por volta desta altura que o autor decide retirar o circunflexo de Pessôa. 
Legenda: Poema "A Ceifeira”, na sua primeira publicação na revista "Terra Nossa”

$4^{6}$

TERRA NOSSA

Os ineditos de José Duro merecem, embora poucos e truncados, o carinho d'uma compilaçáo. Cuido que o sr. Albino Forjaz de Sampaio a deseja fazer e seria um pleonasmo asseverar-lhe aqui que prestará com isso um serviço muito prestimoso e muito grato á menroria do saudoso esquecido e á litteratura nacional. Em Portalegre, pessoas amigas fallaram-me na existencia d'um poema $A N^{\prime} A T^{\prime} K A$ e d'uma serie de sonetos «A Aza do Corvom. Nos manuscriptos que nos restam nấo lhes descobri a menor referencia. A familia do poeta ignora onde essas producçóes possam existir.

Se algum dos intimos de José Duro porventura recatadamente as guarda, bom seria

Lisboa - 1916 que as fizesse publicar, náo representando 0 facto qualquer desdoiro para o grande arartista do *Fels.

Diz-se que houve já quem se servisse de sonetos de José Duro para se arrrebicar com gallas que năo possue. E' um precalço que succede a toda a gente, com talento ou sem elle, n'esta pobre terra de Portugal, triste alfobre d'atavismos excepcionaes.

A alma de José Duro, do Paiz do Alem, relevará aos pobres d'espirito as consequencias da sua estructura natural, como releverá de certo a este pobre amigo o modesto apontoado de notas e commentarios que em sua homenagem, n'esta revista, sacrilegamente compoz.

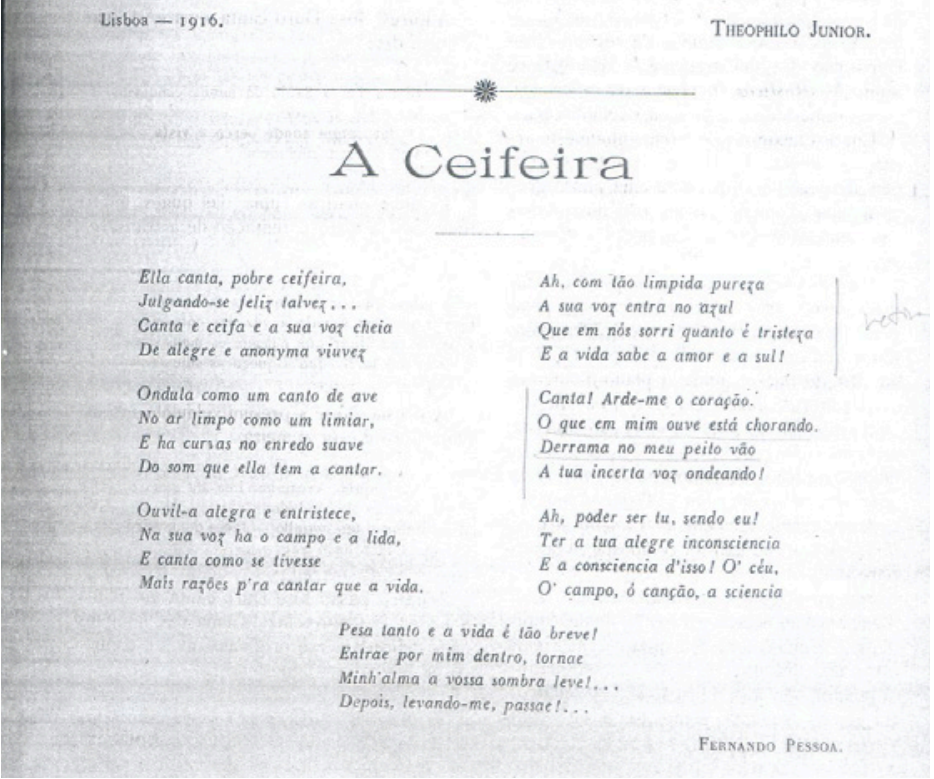

Diz o 'Ponto Final', última página da revista, do primeiro número:

Entrou o mês de maio, o mês da Vida. Entrou o mês de Maio, o mês das primeiras calmas, o mês das feiras, o mês das touradas, o mês das flores, o mês da cor. Entrou o mês de maio e com ele entrou a publicar-se o nosso modesto mensário cujas páginas traçadas sob a emoção nostálgica da Charneca-Mãe representam os primeiros passos de uma inspiração a caminho de um objectivo maior. Um mensário é necessariamente um jornal que se publica menos vezes do que o comum dos jornais, como o poderia afirmar catedrático qualquer Monsieur de la Palisse em que é fértil esta pequenina terra de Portugal. [...]

Os objectivos traçados não são muito diferentes daqueles que lemos em Gente Lusa, se compararmos os dois editoriais - enquanto 
a revista do Porto nos assegura não ter qualquer programa - assunção reiterada no início da segunda série, em 1917-aqui o mensário é caracterizado como 'modesto', pretendendo apenas por em dia uma 'emoção nostálgica' desta região do país. Ambas, no entanto, reiteram que há um caminho maior, mais ambicioso: o culto nobilíssimo da tradição, no caso de Gente Lusa, e a inspiração 'a caminho de um 'objectivo maior' no caso de Terra Nossa.

Passemos então a entrever a estética das capas, e a forma como esta vai no mesmo sentido. De uma forma geral, esta apresenta-se sem muitos pormenores, com alusão à vida alentejana. As cores são muito suaves - azul celeste para a primeira capa, amarelo limão na segunda e de tons pastel na terceira. No primeiro número, quem desenha a capa é Martinho Gomes da Fonseca, de 25 anos na altura (1890-1972), discípulo de Columbano Bordalo Pinheiro. No número dois, da capa diz o Ponto Final, última página da revista, "O desenho da capa d'este número da Terra Nossa é um motivo alentejano, que Saavedra Machado tirou do natural em pleno campo. Figura a casa do ferreiro, em Santa Victoria do Ameixial, pequenina aldeia, repleta de evocações, no extremo do concelho de Estremoz". Já o terceiro e número final, é da autoria de novo discípulo de Columbano, Gil Romero, e temos a informação que o original é uma aguarela a cores.

\section{Legenda: Capas dos 3 números da revista "Terra Nossa”}
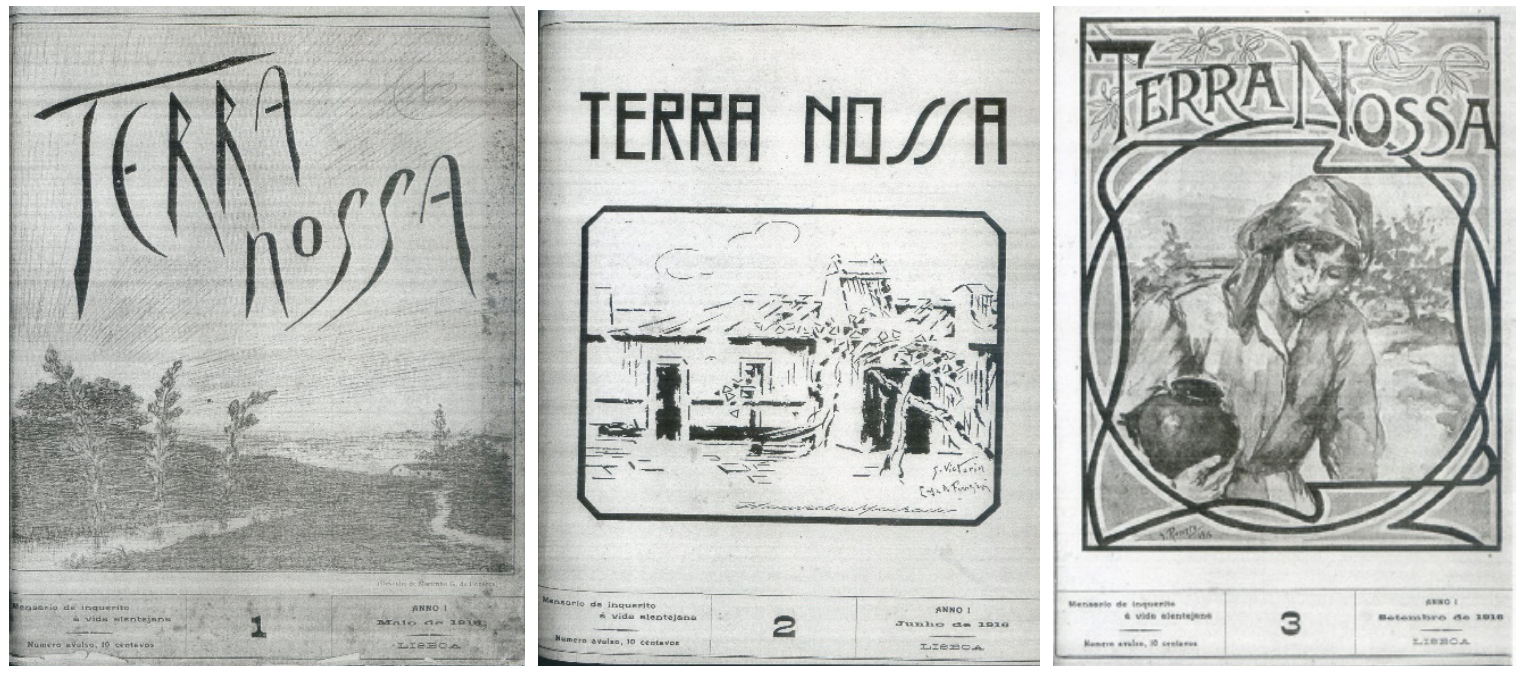

Em todos os números há uma fotografia de um ilustre poeta - Fialho de Almeida, escritor alentejano recentemente falecido, no primeiro número, o Conde de Monsaraz no segundo e José Duro, poeta alentejano bem conhecido da altura, no terceiro.
Mais uma vez, a estratégia do ponto de vista do conteúdo é a mesma de Gente Lusa: enaltecer o talento da terra, ou da 'CharnecaMãe' como nos é dito no editorial, seja ele o talento coevo, seja os nomes incontornáveis do passado recente. 
Do ponto de vista literário, e para além de Pessoa, são ilustres os colaboradores dos outros números desta revista. António Sardinha colabora com um extenso 'Poema do Outono' "Vem a subir o Outono, amiga, como será o nosso envelhecer...” É o próprio António Sardinha que no segundo número consagra várias páginas ao Conde de Monsaraz, páginas autobiográficas que analisam a obra do autor, seguido daquele que é o 'ultimo poema do Conde de Monsaraz'; um artigo sobre Fialho de Almeida (1857-1911), os seus últimos dias, da autoria de Garcia Pulido, seguido de um inédito do autor alentejano e, finalmente, sonetos decadentistas de Hernâni Cidade e de Alberto de Castro Osório.

Brito Camacho fala do 'Celeiro de Portugal'. Número com poemas inéditos de José Duro e parecendo a ele consagrado. Teófilo Júnior faz uma descrição sumária deste autor, analisando a sua obra comparativamente a outros, como Poe. António Ferro tem um poema dedicado a Augusto Mira da Silva, intitulado 'Carpideiras do Sol morto'. No cabeçalho uma versão de Millet dos respigadores, ilustrando o poema. O número termina com um artigo sobre Eça de Queirós em Évora, com trechos das crónicas escritas para o Distrito de Évora pelo escritor de Vila do Conde.

Parece-me assim, por esta brevíssima análise de revistas literárias do ano de 1916 que Exílio e Centauro não estariam sozinhas na sua invectiva nacionalista e decadentista. Por um lado parece haver um desejo de ser fiel à tradição nas três revistas mais de perto analisadas, de forma a assim estar mais atento ao presente das coisas simples, e assim mais actual. Por outro, assiste-se a um outro movimento paralelo de sacralizar e canonizar autores finisseculares e ainda pertencentes ao século anterior, de forma a cimentar as fundações dessa mesma tradição - autores que, como se viu, em tudo têm a ver com a terra gloriosa de Portugal e do local de onde vieram.

\section{REFERÊNCIAS BibLIOGRÁFICAS MoNOGRAFIAS:}

GUimarães, Fernando, Simbolismo, Modernismo, Vanguardas, Porto, Lello \& Irmãos, 1992 [1982].

PIRES, Daniel, Dicionário da Imprensa Periódica Literária, 1900-1940, primeiro tomo, Lisboa, Grifo, 1996.

ROCHA, Clara, Revistas Literárias do século XX em Portugal, Lisboa, INCM, 1985.

VASCONCELOS, Ana Isabel et al, o Teatro de Lisboa no Tempo da Primeira República, Lisboa, INCM, 2004.

Revistas literárias:

Exílio: Revista Mensal de Arte, Lettras e Sciencias, Dir. lit. Augusto de Santa-Rita, Lisboa, Rodrigues e $C^{a}$, 1916. (número único).

Camilliana: Archivo de Materiaes para um Monumento Litterario ao Grande Escriptor, Dir. lit. Alfredo de Faria, Porto, A.F., 1916. (número único).

Centauro: Revista trimestral de Literatura, Dir. lit. Luís de Montalvor, Typographia do Annuario Commercial, 1916. (número único).

Gente Lusa: Arquivo de Letras e Artes, Dir. Carlos de Morais, Zacarias Correia, Praia da 
Granja, António Reis, 1916-17. (10 números, 2 séries)

Terra Nossa, Dir. lit. António Lobato Adegas, Lisboa, Typ. Annuario Commercial, 1916. (3 números).

Recebido para publicação em 29 out. 2016.

Aceito para publicação em 10 jan. 2017. 